\title{
Differential Effects of Combination of Renin-Angiotensin- Aldosterone System Inhibitors on Central Aortic Blood Pressure: A Cross-Sectional Observational Study in Hypertensive Outpatients
}

\author{
Akshyaya Pradhan $\left(\mathbb{D}\right.$, Pravesh Vishwakarma, Monika Bhandari, Rishi Sethi ${ }^{(D)}$, \\ and Varun Shankar Narain
}

Department of Cardiology, King George Medical University, Shah Mina Road, Chowk, 226003, Lucknow, Uttar Pradesh, India

Correspondence should be addressed to Rishi Sethi; drrishisethi1@gmail.com

Received 27 April 2020; Revised 5 July 2020; Accepted 19 August 2020; Published 8 September 2020

Academic Editor: Haruhito A. Uchida

Copyright ( 92020 Akshyaya Pradhan et al. This is an open access article distributed under the Creative Commons Attribution License, which permits unrestricted use, distribution, and reproduction in any medium, provided the original work is properly cited.

\begin{abstract}
Background. Central aortic blood pressure (CABP) indices, central hemodynamics, and arterial stiffness are better predictors of cardiovascular events as compared with brachial cuff pressure measurements alone. The present study is aimed at assessing the effects of different antihypertensive drug combination regimens involving renin-angiotensin-aldosterone system (RAAS) inhibitors on CABP indices in Indian patients with hypertension. Methods. This was a cross-sectional, single-center study conducted in patients treated for hypertension for $>6$ weeks using different treatment regimens involving the combination of RAAS inhibitors with drugs from other classes. CABP indices, vascular age, arterial stiffness, and central hemodynamics were measured in patients using the noninvasive Agedio B900 device (IEM, Stolberg, Germany) and compared between different treatment regimens. Results. A total of 199 patients with a mean age of $54.22 \pm 10.15$ years were enrolled, where $68.8 \%$ had hypertension for over three years and $50.25 \%$ had their systolic blood pressure $(\mathrm{SBP})<140 \mathrm{mmHg}$. Combination treatment with angiotensin II receptor blockers (ARBs) and angiotensin-converting enzyme inhibitors (ACEIs) was given to $77.9 \%$ and to $20.1 \%$ patients, respectively. The mean vascular age was higher than the actual age (58.13 \pm 12.43 vs. $54.22 \pm 10.15, p=0.001)$. The SBP and diastolic blood pressure (DBP) levels in patients treated with ACEI-based combinations were lower than those in patients treated with ARB-based combinations $(p<0.05)$. The mean central pulse pressure amplification, augmentation pressure, and augmentation index were lower in patients treated with ACEI-based combinations than those treated with other treatments $(p=0.001)$. In a subgroup analysis, patients given perindopril and calcium channel blockers (CCBs) or diuretics had significantly lower CABP and pulse wave velocity than those given other treatments $(p<0.05)$. A total of $6.5 \%$ patients experienced any side effects. Conclusion. The majority of central hemodynamic parameters, including vascular age, were found to improve more effectively in patients treated with ACEIs than with ARBs. Our results indicate a gap between routine clinical practice and evidence-based guidelines in Indian settings and identify a need to reevaluate the current antihypertensive prescription strategy.
\end{abstract}

\section{Introduction}

Hypertension is one of the most common causes of premature death worldwide according to the World Health Organization [1]. Globally, hypertension is estimated to afflict nearly one billion people, accounting for $26 \%$ of the population, and is a primary modifiable risk factor for stroke and heart disease, which are among the top leading causes of deaths worldwide [2]. The overall burden of hypertension in India is $29.8 \%$, which translates to $33.8 \%$ prevalence in urban population and $27.6 \%$ in rural population [3]; therefore, it continues to be a major public health challenge.

Conventionally, hypertension is managed on the basis of brachial blood pressure (BP). 
Nevertheless, emerging evidence shows that central aortic blood pressure (CABP) predicts cardiovascular events more effectively than brachial blood pressure [4]. In addition to conventional BP measurements, other variables such as advanced hemodynamic parameters, including stroke volume, cardiac output, peripheral resistance, arterial stiffness (as measured by pulse wave velocity), and vascular age, are also analyzed to obtain critical information about cardiovascular health $[5,6]$. Moreover, studies have shown that the predictive value of CABP is independent of the corresponding brachial blood pressure [7-10]. Although CABP has been demonstrated to be a valuable predictor of cardiovascular outcomes, its use in the routine clinical practice is very confined, which limits its prognostic utility.

Renin-angiotensin-aldosterone system (RAAS) inhibitors, calcium channel blockers (CCBs), diuretics, and $\beta$ blockers are the commonly recommended antihypertensive drugs. These drugs have different modes of action, which are conventionally studied with respect to peripheral BP. However, evidence shows that despite the similar reduction in the peripheral $\mathrm{BP}$, they have differential effects on the central BP [11-13]. These effects have been studied extensively globally; the data originating from India are scarce owing to the limited use of CABP as a prognostic tool in routine practice. Technological advances have led to the development of various noninvasive devices to estimate central BP, which renders these parameters amenable to a multitude of patient populations and disease states [14-17]. Using the cuff-based Agedio B900 (monitor PWA) device integrated with Agedio K500, we evaluated the effects of various antihypertensive drugs on CABP indices in hypertensive outpatients in routine clinical practice in India.

\section{Materials and Methods}

2.1. Study Design and Participants. This was a cross-sectional observational study conducted at a Tertiary Care Medical University, Lucknow, from January 2017 to December 2018. A total of 240 patients were screened; of which, 199 patients who were on stable antihypertensive dose for over six weeks or who were previously or recently treated with antihypertensive medications were included in the study. Target BP control was defined as brachial SBP $<140 \mathrm{mmHg}$ or DBP $<90 \mathrm{mmHg}$ . Patients with liver dysfunction, signs and symptoms of heart failure, chronic kidney disease (CKD), or systemic inflammation and infection were excluded from the study.

The study was approved by the institutional ethics committee. Written informed consent was obtained from all patients.

2.2. Study Size. Eligible patients coming to the outpatient department (OPD) during the defined time period were taken for the study. The approximate number according to previous medical records is around $180-200$ patients.

2.3. Measurement of Hemodynamic Parameters. The noninvasive Agedio B900 device (IEM, Stolberg, Germany), which works based on systolic pressure amplification phenomenon, was used to measure peripheral BP, central BP, advanced
TABLE 1: Demographic characteristics of the analyzed population.

\begin{tabular}{lc}
\hline Total number of patients $(n=199)$ & \\
\hline Gender, male & $118(59.3)$ \\
Age, 28-78 years & $54.22 \pm 10.15^{*}$ \\
Profile of controlled hypertension & $72(36.2)$ \\
$\quad$ Duration of hypertension & \\
$\leq 3$ & $62(31.2)$ \\
$>3$ & $137(67.8)$ \\
Profile of side effects & $13(6.5)$ \\
Risk factors (\%) & \\
Family history of hypertension & $138(69.3)$ \\
Smoking & $37(18.6)$ \\
Tobacco chewing & $30(15.1)$ \\
Diabetes & $11(5.5)$ \\
\hline
\end{tabular}

$n$ : frequency; \%: percentage; $*$ : mean $\pm \mathrm{SD}$.

TABLe 2: Drug treatment in the study population.

\begin{tabular}{lc}
\hline Combinations & Total number of patients $(n=199)$ \\
\hline ACEI+CCB & $13(6.5)$ \\
ACEI+diuretics & $27(13.6)$ \\
ARB+CCB & $65(32.7)$ \\
ARB+diuretics & $90(45.2)$ \\
Others & $4(2.0)$ \\
\hline
\end{tabular}

$n$ : frequency; ACEI: angiotensin-converting enzyme inhibitor; ARB: angiotensin II receptor blocker; CCB: calcium channel blocker.

hemodynamic indices, arterial stiffness, and vascular age [18-21]. The various indices measured were as follows: peripheral and central systolic BP (SBP) and diastolic BP (DBP), pulse pressure (PP), mean arterial pressure (MAP), PP amplification (PPA), age of vessels (older than biological age or same as the biological age, years), peripheral resistance (PR), cardiac output (CO), stroke volume (SV), cardiac index (CI), augmentation pressure (AP), augmentation index (AI), reflection coefficient (RC), and pulse wave velocity (PWV). These indices were compared in patients receiving different antihypertensive drug combinations. In all patients, BP and PWV were measured in an ideal environment (sitting and quiet position). A subgroup analysis was also carried out to compare the CABP indices in patients who were on the ACEI perindopril with the rest of the patients.

2.4. Statistical Analysis. Descriptive statistics was performed on all demographic and clinical measurements. Baseline patient characteristics were reported as percentages for categorical variables and mean \pm standard deviation for continuous variables. Data comparing means of three or more groups were analyzed using the two-way analysis of variance (ANOVA) test (SPSS Inc., Chicago, USA), and data involving comparison of means between only two groups were analyzed using $t$-test. Post hoc analysis of various groups analyzed by ANOVA test was also performed. All $p$ values less than 0.05 were considered significant. 
TABLE 3: Peripheral blood pressure measurements among various drug combinations.

\begin{tabular}{lcccc}
\hline Treatment group & SBP $(\mathrm{mmHg})$ mean \pm SD & DBP $(\mathrm{mmHg})$ mean \pm SD & MAP $(\mathrm{mmHg}) \mathrm{mean} \pm \mathrm{SD}$ & $\mathrm{PP}(\mathrm{mmHg}) \mathrm{mean} \pm \mathrm{SD}$ \\
\hline ACEI+CCB & $134.31 \pm 11.35$ & $80.77 \pm 09.05$ & $105.23 \pm 08.87$ & $53.54 \pm 10.22$ \\
ACEI+diuretics & $134.93 \pm 21.96$ & $88.04 \pm 12.30$ & $109.44 \pm 15.52$ & $46.89 \pm 15.10$ \\
ARB+CCB & $143.72^{*} \pm 18.62$ & $90.78 \pm 15.27^{*}$ & $114.25 \pm 14.51^{*}$ & $52.51 \pm 16.54$ \\
ARB+diuretics & $141.69 \pm 18.49$ & $86.62 \pm 11.65$ & $111.63 \pm 13.85$ & $55.24 \pm 13.58^{*}$ \\
Others & $154.25 \pm 22.69$ & $104.50 \pm 22.81$ & $127.25 \pm 22.74$ & $49.75 \pm 01.26$ \\
$p$ value & 0.027 & 0.009 & 0.014 & 0.031 \\
\hline
\end{tabular}

$n$ : frequency; ACEI: angiotensin-converting enzyme inhibitor; ARB: angiotensin II receptor blocker; CCB: calcium channel blocker; SBP: systolic blood pressure; DBP: diastolic blood pressure; MAP: mean arterial pressure; PP: pulse pressure. *Statistically significant; PP is defined as difference in mean SBP and DBP; MAP is defined as DBP + PP/3.

\section{Results}

3.1. Demographic and Clinical Characteristics. A total of 199 patients were analyzed in the study; out of them $59.3 \%$ were men. The age of patients ranged from 27 to 78 years, with the mean age $( \pm S D)$ being $54.2 \pm 10.15$ years. Only $36.2 \%$ patients had controlled hypertension. A majority of the patients $(67.8 \%)$ had hypertension for or over three years. The family history of hypertension was seen in $69.3 \%$ patients, $18.6 \%$ were smokers, $15.1 \%$ chewed tobacco, and $5.5 \%$ had diabetes (Table 1). A total of 13 (6.5\%) patients experienced side effects, three cases of cough, four cases of edema, and six patients reported other side effects.

All the 199 patients were on antihypertensive medication; $45.2 \%$ were on angiotensin II receptor blocker (ARB) and diuretics (ARB+diuretics), 32.7\% were on $\mathrm{ARB}$ and $\mathrm{CCB}$ $(\mathrm{ARB}+\mathrm{CCB}), 13.6 \%$ were on angiotensin-converting enzyme inhibitor (ACEI) and diuretics (ACEI+diuretics), and 6.5\% were on ACEI and CCB (ACEI+CCB), while $2 \%$ were on other drugs (Table 2). Subgroup analyses revealed that a total of 22 patients were on the long-acting ACEI, perindopril.

3.2. Peripheral Blood Pressure Measurements. Overall, 100 patients had their SBP $<140 \mathrm{mmHg}$ and 109 patients had their DBP $<90 \mathrm{mmHg}$. As shown in Table 3 and Figure 1, the mean peripheral SBP and DBP were significantly different among the treatment groups $(p=0.027)$. The mean SBP was the lowest in patients receiving ACEI+CCB $(134.31 \pm 11.35 \mathrm{mmHg}$ ), followed by those in the ACEI +diuretics $\quad(134.93 \pm 21.96 \mathrm{mmHg}), \quad \mathrm{ARB}+$ diuretics $(141.69 \pm 18.49 \mathrm{mmHg}), \mathrm{ARB}+\mathrm{CCB}(143.72 \pm 18.62 \mathrm{mmHg})$, and $A R B+$ diuretics $(141.69 \pm 18.49 \mathrm{mmHg})$ groups. The mean peripheral DBP was $90.78 \mathrm{mmHg}$ in the ARB+CCB patient group, which was significantly higher $(p=0.009)$ than $80.77 \mathrm{mmHg}$ in the ACEI+CCB group. The peripheral DBP between other groups was comparable. The mean peripheral MAP was $114.25 \mathrm{mmHg}$ in the $\mathrm{ARB}+\mathrm{CCB}$ group, which was significantly higher $(p=0.014)$ than $105.23 \mathrm{mmHg}$ in the $\mathrm{ACEI}+\mathrm{CCB}$ group; other treatment groups had comparable mean peripheral MAP. The mean peripheral PP was $55.24 \mathrm{mmHg}$ in the $\mathrm{ARB}+$ diuretics group, which was significantly higher $(p=0.031)$ than $46.89 \mathrm{mmHg}$ in the ACEI +diuretics group, while that of others was comparable (Table 3). Overall, all the peripheral BP measurements were noted to have improved in patients on ACEIs compared with those on ARBs.

3.3. Central Blood Pressure Measurements. The mean central SBP in the ACEI+CCB group (119.92 $\pm 10.39 \mathrm{mmHg})$ was significantly lower than that in the ARB+CCB group $(132.69 \pm 18.26 \mathrm{mmHg})(p=0.001)$; central SBP in others was comparable. A similar pattern was observed for the mean central DBP (ACE+CCB: $82.38 \pm 09.33 \mathrm{mmHg}$ vs. ARB+CCB: $92.95 \pm 15.33 \mathrm{mmHg}(p=0.001))$. Although the mean central $\mathrm{PP}$ was higher in the ARB+CCB $(39.57 \pm 15.53 \mathrm{mmHg})$ and $\mathrm{ARB}+$ diuretics $(39.42 \pm 09.31 \mathrm{mmHg})$ groups than in the $\mathrm{ACEI}+\mathrm{CCB} \quad(37.23 \pm 03.11 \mathrm{mmHg})$ and ACEI+diuretics $(35.33 \pm 10.12 \mathrm{mmHg})$ groups, these differences were not significant $(p>0.05)$. The mean central PPA was $1.44 \pm 0.21$ in the ACEI+CCB group and $1.40 \pm 0.16$ in the ARB+diuretics group, which was significantly higher $(p=0.001)$ than 1.30 \pm 0.13 in the ACEI+diuretics group. The mean $\mathrm{HR}$ was $92.63 \pm 14.12$ beats $/ \mathrm{min}$ in the ARB+CCB group, which was significantly higher $(p=0.006)$ than $68.56 \pm 05.52$ beats $/ \mathrm{min}$ in the ACEI+diuretics group and $78.11 \pm 12.47$ beats $/ \mathrm{min}$ in the ARB+diuretics group (Table 4, Figure 2). Similar to the peripheral $\mathrm{BP}$ readings, the central $\mathrm{BP}$ levels were higher in patients who were on ARB than those on ACEI.

3.4. Vascular Age. In the overall cohort, the mean vascular age of patients was significantly higher than the average actual age $(58.13 \pm 12.43$ years vs. $54.22 \pm 10.15$ years $(p=0.001))$. The mean vascular age was the lowest in the patients in the ACEI + diuretics treatment group $(53.30 \pm 13.38$ years $)$. The mean vascular age was $60.55 \pm 10.77$ years in the $\mathrm{ARB}+\mathrm{CCB}$ group and $60.85 \pm 09.25$ years in the ACEI+CCB group, which was significantly higher $(p=0.034)$ than $53.30 \pm 13.38$ years in the ACEI+diuretics group and for others groups was comparable (Table 5).

3.5. Arterial Stiffness. The measurement of arterial stiffness via $\mathrm{PWV}, \mathrm{AP}$, and $\mathrm{AC}$ gives an assessment of the vascular age. The mean AP was significantly lower in the ACEI +diuretics group $(7.11 \pm 04.67 \mathrm{mmHg})$ than $11.97 \pm 09.71$ $\mathrm{mmHg}$ in the ARB+CCB group $(p=0.001)$, and it was comparable between other treatment groups. The mean AI was $17.67 \% \pm 12.16 \%$ in the ACEI+diuretics group, which was significantly lower than $34.82 \% \pm 15.05 \%$ in the ARB+CCB group and $25.11 \% \pm 12.67 \%$ in the $\mathrm{ARB}+$ diuretics group, 


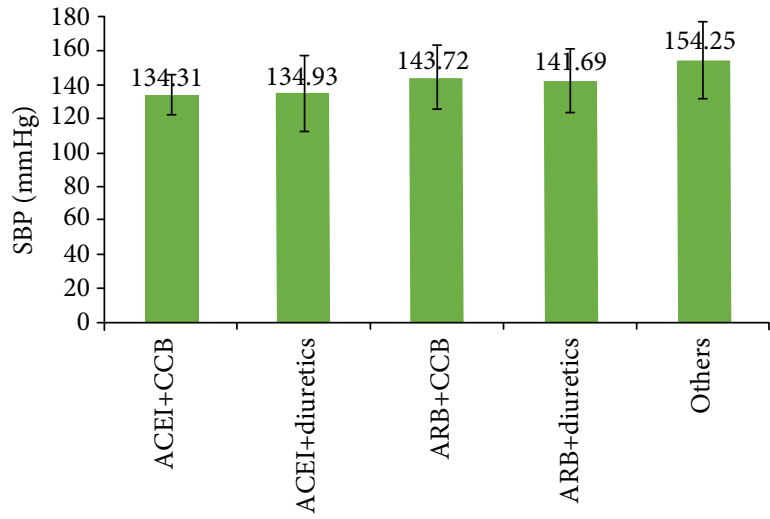

(a) Peripheral SBP measurements

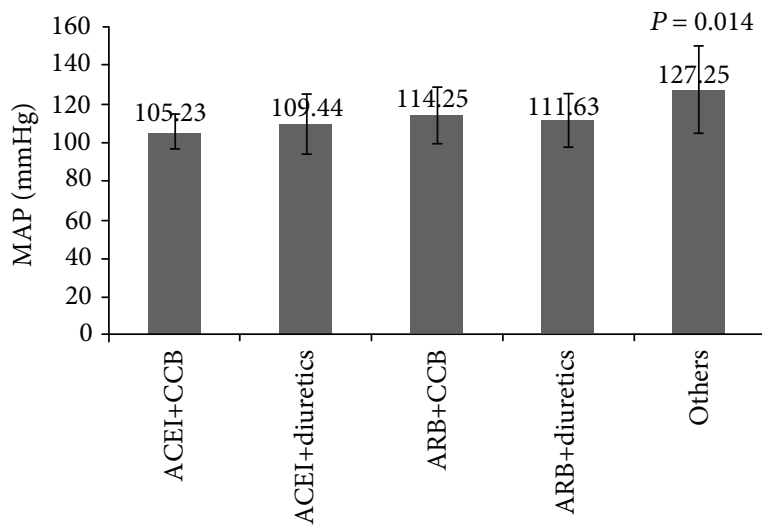

(c) Peripheral MAP measurements

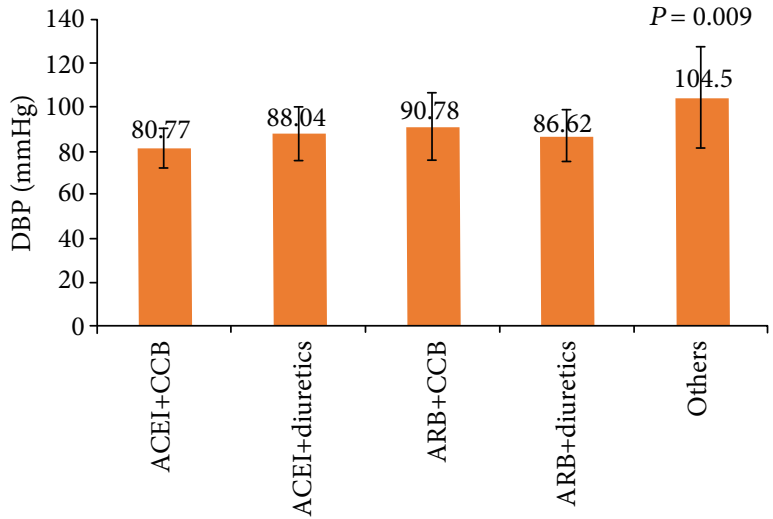

(b) Peripheral DBP measurements

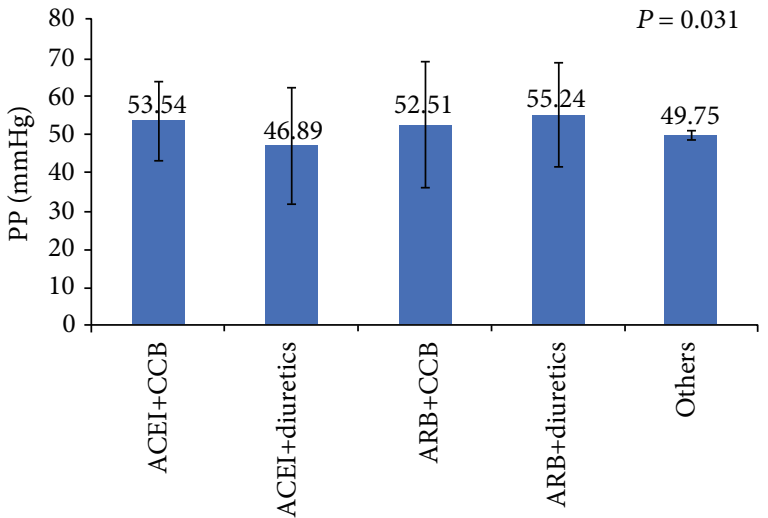

(d) Peripheral PP measurements

FIGURE 1: Peripheral blood pressure measurements among various antihypertensive drug combinations. SBP: systolic blood pressure; DBP: diastolic blood pressure; MAP: mean arterial pressure; PP: pulse pressure.

TABLE 4: Central blood pressure measurements.

\begin{tabular}{lccccc}
\hline Treatment group & $\mathrm{SBP}(\mathrm{mmHg})$ mean $\pm \mathrm{SD}$ & $\mathrm{DBP}(\mathrm{mmHg})$ mean $\pm \mathrm{SD}$ & $\mathrm{PP}(\mathrm{mmHg})$ mean $\pm \mathrm{SD}$ & $\mathrm{PPA}$ mean $\pm \mathrm{SD}$ & $\mathrm{HR}(1 / \mathrm{m}) \mathrm{mean} \pm \mathrm{SD}$ \\
\hline ACEI+CCB & $119.92 \pm 10.39$ & $82.38 \pm 09.33$ & $37.23 \pm 03.11$ & $1.44 \pm 0.21^{*}$ & $88.46 \pm 12.26$ \\
ACEI+diuretics & $124.48 \pm 19.46$ & $89.11 \pm 12.47$ & $35.33 \pm 10.12$ & $1.30 \pm 0.13$ & $68.56 \pm 05.52$ \\
ARB+CCB & $132.69 \pm 18.26^{*}$ & $92.95 \pm 15.33^{*}$ & $39.57 \pm 15.53$ & $1.38 \pm 0.20$ & $92.63 \pm 14.12^{*}$ \\
ARB+diuretics & $127.63 \pm 15.80$ & $88.16 \pm 11.63$ & $39.42 \pm 09.31$ & $1.40 \pm 0.16$ & $78.11 \pm 12.47$ \\
Others & $143.75 \pm 26.54$ & $106.50 \pm 23.17$ & $37.25 \pm 04.27$ & $1.50 \pm 0.32$ & $90.00 \pm 21.69$ \\
$p$ value & 0.001 & 0.001 & - & 0.001 & 0.006 \\
\hline
\end{tabular}

$n$ : frequency; ACEI: angiotensin-converting enzyme inhibitor; ARB: angiotensin II receptor blocker; CCB: calcium channel blocker; SBP: systolic blood pressure; DBP: diastolic blood pressure; PP: pulse pressure; PPA: pulse pressure amplification; m: meters. ${ }^{*}$ Statistically significant; PP is defined as difference in mean SBP and DBP; PPA is defined as ([peripheral PP - central PP/central PP] $\times 100$ ) by indirect derived calculations.

respectively $(p=0.001)$. The mean $\mathrm{RC}$ was $70.56 \%$ in the ACEI+diuretics group, which was significantly higher than $66.33 \%$ in the $\mathrm{ARB}+$ diuretics group $(p=0.026)$. As for mean $\mathrm{PWV}$, although it was lower in the $\mathrm{ARB}+$ diuretics group than in the $\mathrm{ACEI}+\mathrm{CCB}, \mathrm{ACEI}+$ diuretics, and $\mathrm{ARB}+\mathrm{CCB}$ groups, the difference was not significant (Table 6).

3.6. Advanced Central Hemodynamic Parameters. As indicated in Table 7 , the mean PR was $1600.85 \pm 118.92$ dyn $* \mathrm{~s} / \mathrm{cm}^{5}$ in the ACEI+CCB group, and it was significantly lower $(p=0.001)$ than $1853.30 \pm 236.01 \mathrm{dyn} * \mathrm{~s} / \mathrm{cm}^{5}$ in the ACEI+diuretics group, while the PR of other groups was com- parable. The mean $\mathrm{CO}$ was $5.09 \pm 0.80 \mathrm{~mL} / \mathrm{min}$ in the $\mathrm{ARB}$ $+\mathrm{CCB}$ group, which was significantly higher $(p=0.001)$ than that in the ACEI+diuretics group and the $\mathrm{ARB}+$ diuretics group $(4.33 \pm 0.63 \mathrm{~mL} / \mathrm{min}$ and $4.60 \pm 0.67 \mathrm{~mL} / \mathrm{min}$, respectively). The mean SV was $63.41 \pm 07.61 \mathrm{~mL}$ in patients from the ACEI+diuretics group, which was significantly higher $(p=0.001)$ than that in patients from the ACEI+CCB and $\mathrm{ARB}+\mathrm{CCB}$ groups $(54.09 \pm 04.93 \mathrm{~mL}$ and $55.54 \pm 08.37 \mathrm{~mL}$, respectively), while the $\mathrm{SV}$ of other groups was comparable. The mean CI was $3.00 \pm 0.42 \mathrm{~L} / \mathrm{min} * \mathrm{~L} / \mathrm{m}^{2}$ in the ARB $+\mathrm{CCB}$ group, and it was significantly higher $(p=0.001)$ than that in the ACEI+diuretics and ARB+diuretics groups 


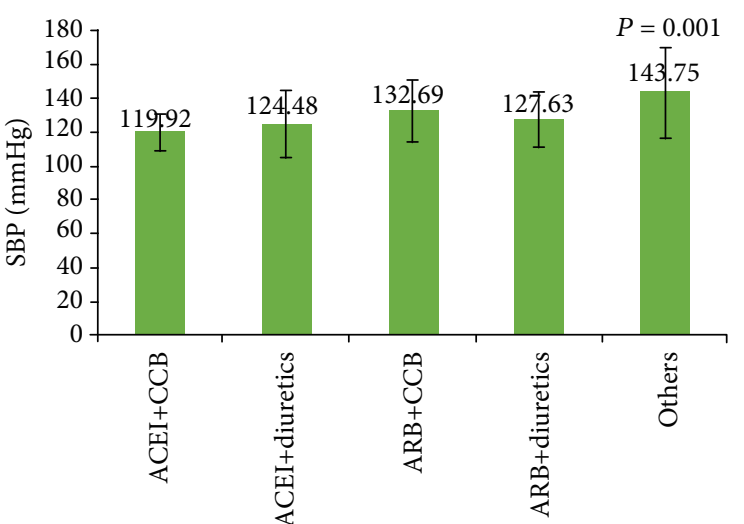

(a) Central SBP measurements

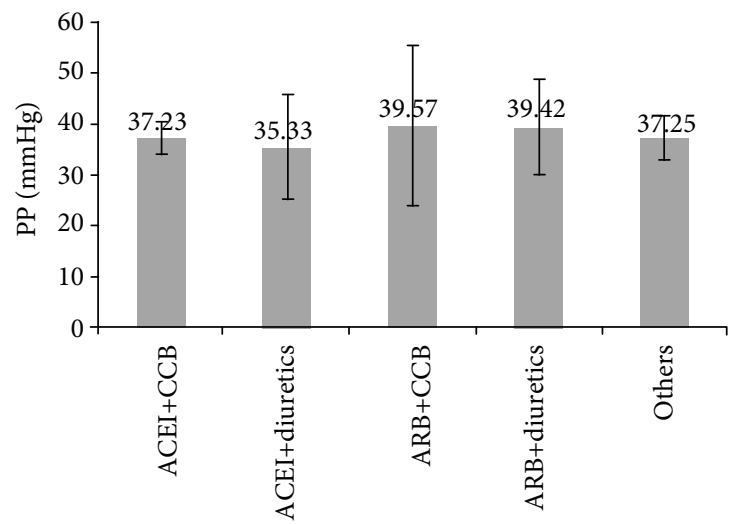

(c) Central PP measurements

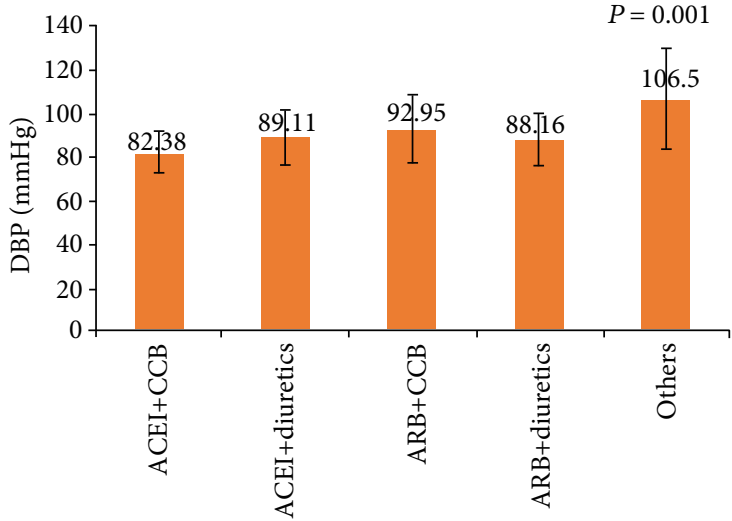

(b) Central DBP measurements

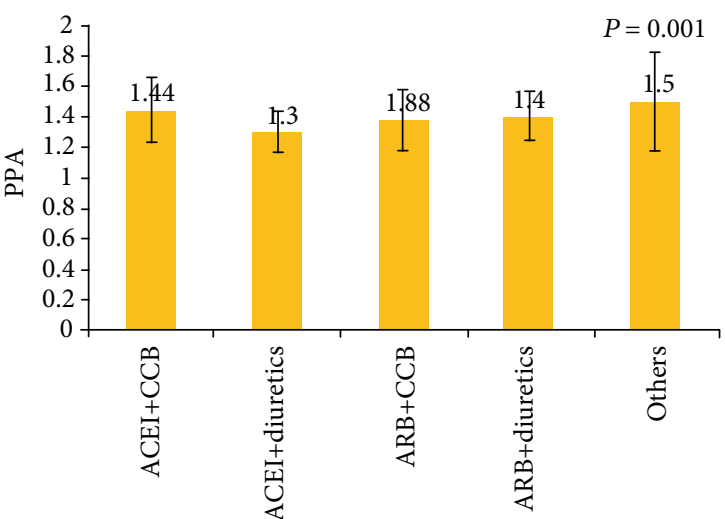

(d) Central PPA measurements

FIgURE 2: Central blood pressure measurements among various antihypertensive drug combinations. SBP: systolic blood pressure; DBP: diastolic blood pressure; PP: pulse pressure; PPA: pulse pressure augmentation.

TABLE 5: Measurement of vascular age.

\begin{tabular}{lc}
\hline Mean actual age vs. vascular age (years) & \\
\hline Actual age & $54.22 \pm 10.15$ \\
Vascular age & $58.13 \pm 12.43^{*}$ \\
Treatment group & \\
ACEI+CCB & $60.85 \pm 09.25$ \\
ACEI+diuretics & $53.30 \pm 13.38$ \\
ARB+CCB & $60.55 \pm 10.77^{\$}$ \\
ARB+diuretics & $57.40 \pm 13.32$ \\
Others & $58.75 \pm 13.20$
\end{tabular}

$n$ : frequency; ACEI: angiotensin-converting enzyme inhibitor; ARB: angiotensin II receptor blocker; CCB: calcium channel blocker. ${ }^{*} p<0.001$; $\$ p=0.034$; vascular age (years) is the age of vessels older than biological age or the same as the biological age.

$\left(2.44 \pm 0.40 \mathrm{~L} / \mathrm{min} * \mathrm{~L} / \mathrm{m}^{2}\right.$ and $2.68 \pm 0.41 \mathrm{~L} / \mathrm{min} * \mathrm{~L} / \mathrm{m}^{2}$, respectively).

3.7. Subgroup Analysis. The mean values of outcome measure in patients on perindopril and the rest of the treatment groups are summarized in Table 8. Patients who were taking perindopril had significantly lower CABP and PWV than those with other treatments $(p<0.05)$.

\section{Discussion}

Drug combinations involving RAAS inhibitors are commonly used treatment modality for managing patients with hypertension [22-24]. CABP is a better indicator of future cardiovascular events than brachial pressure [9, 10]. However, there is scarcity of evidence for the differential effect of various drug combinations on different CABP indices in an Indian population. In this study, our main objective was to evaluate the effect of different antihypertensive drug combinations on various CABP indices in Indian patients having hypertension and compare the results between different treatment groups. Our study showed that out of the four RAAS-based treatment groups, effective improvement of the CABP indices was observed in patients who were being treated with ACEI either in a two-drug combination or alone. This has also been indicated by the subgroup analysis that CABP indices were significantly improved with perindopril, which is a type of long-acting ACEI. The majority of patients were on ARBbased combinations (77.9\%), followed by ACEI-based combination $(20.1 \%)$ treatment. Moreover, the BP control rate reported in our study was $36.4 \%$, which is consistent with the low rate $(2.4 \%$ to $38 \%)$ reported for India [25].

Patients receiving combination antihypertensive therapy achieve lower BP levels correlating with a significant reduction in the risk of CV and cerebrovascular events [26-28]. 
TABLE 6: Measurement of arterial stiffness.

\begin{tabular}{lcccc}
\hline Treatment group & $\mathrm{AP}(\mathrm{mmHg})$ mean $\pm \mathrm{SD}$ & $\mathrm{AI}(\%)$ mean $\pm \mathrm{SD}$ & $\mathrm{RC}(\%)$ mean $\pm \mathrm{SD}$ & $\mathrm{PWV}(\mathrm{m} / \mathrm{s}) \mathrm{mean} \pm \mathrm{SD}$ \\
\hline ACEI+CCB & $10.08 \pm 06.29$ & $32.38 \pm 19.27$ & $68.85 \pm 07.06$ & $9.03 \pm 2.28$ \\
ACEI+diuretics & $07.11 \pm 04.67$ & $17.67 \pm 12.16$ & $70.56 \pm 08.45^{*}$ & $8.50 \pm 1.51$ \\
ARB+CCB & $11.97 \pm 09.71^{*}$ & $34.82 \pm 15.05^{*}$ & $66.48 \pm 10.31$ & $8.66 \pm 1.85$ \\
ARB+diuretics & $10.60 \pm 07.31$ & $25.11 \pm 12.67$ & $66.33 \pm 08.91$ & $8.22 \pm 1.67$ \\
Others & $12.25 \pm 05.12$ & $41.00 \pm 14.85$ & $59.25 \pm 13.99$ & $7.98 \pm 0.62$ \\
$p$ value & 0.001 & 0.001 & 0.026 & - \\
\hline
\end{tabular}

$n$ : frequency; ACEI: angiotensin-converting enzyme inhibitor; ARB: angiotensin II receptor blocker; CCB: calcium channel blocker; AP: augmentation pressure; AI: augmentation index; RC: reflection coefficient; PWV: pulse wave velocity; m: meters; $s=$ seconds; ${ }^{*} p=0.001 ;{ }^{*} p=0.026$.

TABLE 7: Advanced hemodynamic measurements.

\begin{tabular}{lcccc}
\hline Treatment group & $\mathrm{PR}\left(\mathrm{dyn} * \mathrm{~s} / \mathrm{cm}^{5}\right)$ mean $\pm \mathrm{SD}$ & $\mathrm{CO}(\mathrm{L} / \mathrm{min})$ mean $\pm \mathrm{SD}$ & $\mathrm{SV}(\mathrm{mL})$ mean $\pm \mathrm{SD}$ & $\mathrm{CI}\left(\mathrm{L} / \mathrm{min}^{2} \mathrm{~L} / \mathrm{m}^{2}\right) \mathrm{mean} \pm \mathrm{SD}$ \\
\hline ACEI+CCB & $1600.85 \pm 118.92$ & $4.92 \pm 0.77$ & $54.09 \pm 04.93$ & $2.95 \pm 0.52$ \\
ACEI+diuretics & $1853.30 \pm 236.01^{*}$ & $4.33 \pm 0.63$ & $63.41 \pm 07.61^{*}$ & $2.44 \pm 0.40$ \\
ARB+CCB & $1718.88 \pm 175.65$ & $5.09 \pm 0.80^{*}$ & $55.54 \pm 08.37$ & $3.00 \pm 0.42^{*}$ \\
ARB+diuretics & $1777.50 \pm 297.42$ & $4.60 \pm 0.67$ & $59.28 \pm 06.82$ & $2.68 \pm 0.41$ \\
Others & $1881.50 \pm 256.91$ & $5.25 \pm 1.68$ & $57.32 \pm 07.92$ & $2.83 \pm 0.76$ \\
\hline
\end{tabular}

$n$ : frequency; ACEI: angiotensin-converting enzyme inhibitor; ARB: angiotensin II receptor blocker; CCB: calcium channel blocker; PR: peripheral resistance; CO: cardiac output; SV: stroke volume; CI: cardiac index; m: meters; dyn: dynes; ${ }^{*} p=0.001$.

Therefore, the majority of clinical practice guidelines recommend combinations of antihypertensive drugs for optimal management [29-31]. Conforming to these guidelines, all the patients received combination antihypertensives, with a majority receiving RAAS in our study. In a meta-analysis, RAAS inhibition resulted in a significant $5 \%$ reduction in all-cause mortality (HR: 0.95, 95\% CI: $0.91-1.00, p=0.032$ ); however, the observed treatment benefit was entirely from the class of ACEIs, with a significant $10 \%$ reduction in allcause mortality (HR: 0.90, 95\% CI: 0.84-0.97, $p=0.004$ ), while ARB treatment did not provide any mortality reduction (HR: 0.99, 95\% CI: 0.94-1.04, $p=0.683$ ) [22]. This difference in effects has been attributed to the different modes of action of ACEIs vs. ARBs primarily because of the pleiotropic effects and beneficial role of the bradykinin pathway with ACEIs [32-34]. Further, the guidelines also recommend preferring ACEIs over ARBs, suggesting that the ARBs should be used in patients with intolerance to ACEIs [35]. The majority of patients (77.9\%) were receiving ARBs, and only $20.1 \%$ were given ACEIs that showed a wide gap in the clinical practice in India. There is a need to reassess the current prescription patterns to ensure that optimal treatment options are prescribed to patients.

The brachial systolic blood pressure (SBP) always remains higher than central aortic SBP due to pulse pressure (PP) amplification that also holds true when the effects of various antihypertensive classes are considered [36-38]. Moreover, we observed similar findings in our study that showed higher brachial BP compared to the corresponding $\mathrm{CABP}$ in all the four treatment groups. Further, both the brachial SBP and central SBP levels were lower in patients receiving ACEI-based combinations compared to those receiving ARB-based combinations. Our results contradict the results reported by Ruilope and Schaefer, showing better reduction in the central $\mathrm{BP}$ with $\mathrm{ARB}$ (olmesartan) than ACEI (perindopril) [39]. Nonetheless, our results should be interpreted cautiously since it was an observational study that did not have sufficient statistical power for such a comparison. As a result of a significant reduction in central BP, the vascular age and augmentation pressure also tended to be lower with ACEI-based combination treatment in our study.

Emerging evidence suggests that the central BP provides additional information regarding cardiovascular risk beyond the peripheral BP. Although our study did not include antihypertensive combination other than those based on RAAS, convincing evidence shows that there are important differences between the classes of antihypertensive drugs regarding their effects on BP amplification. The newer antihypertensive drugs (ACEIs and ARBs) as well as nitrates are more effective with regard to $\mathrm{BP}$ amplification than the older drugs (diuretics and BBs), and there is compelling evidence on the detrimental effect of BBs (mainly atenolol) on central BBs [13]. Collectively, the routine use of CABP could be an effective tool in the optimal management of hypertension.

The major limitation of our study was the cross-sectional design that did not allow observation of baseline and followup data. Other limitations include small number of patients, no biochemical investigations, and limited antihypertensive classes for comparison.

\section{Conclusion}

In summary, the majority of our patients were treated by ARB-based combination of antihypertensives. Despite this, 
TABLE 8: Peripheral and central blood pressure indices in a subgroup of patients treated with perindopril vs. others.

\begin{tabular}{|c|c|c|c|}
\hline & $\begin{array}{l}\text { Perindopril } \\
(n=22) \\
\text { Mean } \pm \text { SD }\end{array}$ & $\begin{array}{c}\text { Others } \\
(n=177) \\
\text { Mean } \pm \text { SD }\end{array}$ & $\begin{array}{c}p \\
\text { value }\end{array}$ \\
\hline \multicolumn{4}{|c|}{ Peripheral blood pressure } \\
\hline $\mathrm{SBP}(\mathrm{mmHg})$ & $127.41 \pm 9.65^{*}$ & $142.92 \pm 19.13$ & $<0.001$ \\
\hline DBP (mmHg) & $83.00 \pm 8.99^{*}$ & $88.79 \pm 13.81$ & 0.012 \\
\hline MAP (mmHg) & $103.27 \pm 7.66$ & $113.18 \pm 14.73$ & - \\
\hline $\mathrm{PP}(\mathrm{mmHg})$ & $44.41 \pm 10.53^{*}$ & $54.06 \pm 14.78$ & $<0.001$ \\
\hline \multicolumn{4}{|c|}{ Central blood pressure } \\
\hline SBP (mmHg) & $117.18 \pm 9.79^{*}$ & $130.11 \pm 17.68$ & $<0.001$ \\
\hline DBP (mmHg) & $84.00 \pm 8.97^{*}$ & $90.27 \pm 13.89$ & 0.005 \\
\hline $\mathrm{PP}(\mathrm{mmHg})$ & $32.86 \pm 5.33^{*}$ & $39.46 \pm 11.91$ & $<0.001$ \\
\hline PPA (mmHg) & $1.33 \pm 0.16$ & $1.39 \pm 0.18$ & - \\
\hline $\mathrm{HR}$ (L/min) & $73.95 \pm 13.72^{*}$ & $83.43 \pm 14.90$ & 0.005 \\
\hline \multicolumn{4}{|l|}{ Arterial stiffness } \\
\hline $\mathrm{AP}(\mathrm{mmHg})$ & $8.59 \pm 5.50$ & $10.82 \pm 8.13$ & - \\
\hline AI (\%) & $16.27 \pm 17.76$ & $28.28 \pm 14.81$ & - \\
\hline $\mathrm{RC}(\%)$ & $72.00 \pm 7.47^{*}$ & $66.35 \pm 9.48$ & 0.003 \\
\hline PWV (\%) & $9.25 \pm 1.81^{*}$ & $14.46 \pm 20.28$ & 0.001 \\
\hline \multicolumn{4}{|c|}{ Advanced hemodynamics } \\
\hline $\mathrm{PR}\left(\right.$ dyn $\left.* \mathrm{~s} / \mathrm{cm}^{5}\right)$ & $1760.1 \pm 216.16$ & $1759.1 \pm 254.98$ & - \\
\hline $\mathrm{CO}(\mathrm{L} / \mathrm{min})$ & $4.4 \pm 0.679^{*}$ & $4.8 \pm 0.7955$ & 0.02 \\
\hline $\mathrm{SV}(\mathrm{mL})$ & $59.15 \pm 6.50$ & $58.12 \pm 7.98$ & - \\
\hline $\begin{array}{l}\mathrm{CI} \\
\left(\mathrm{L} / \mathrm{min} * \mathrm{~L} / \mathrm{m}^{2}\right)\end{array}$ & $2.56 \pm 0.415^{*}$ & $2.79 \pm 0.467$ & 0.02 \\
\hline $\begin{array}{l}\text { Vascular age } \\
\text { (years) }\end{array}$ & $56.13 \pm 12.37$ & $58.53 \pm 12.34$ & - \\
\hline
\end{tabular}

SBP: systolic blood pressure; DBP: diastolic blood pressure; MAP: mean arterial pressure; PP: pulse pressure; PPA: pulse pressure amplification; AP: augmentation pressure; AI: augmentation index; RC: reflection coefficient; PWV: pulse wave velocity, PR: peripheral resistance; CO: cardiac output; SV: stroke volume; CI: cardiac index; m: meters; dyn: dynes; s: seconds. * Statistically significant; PP is defined as difference in mean SBP and DBP; MAP is defined as DBP + PP/3; PPA is defined as ([peripheral PP - central $\mathrm{PP} /$ central $\mathrm{PP}] \times 100$ ) by indirect derived calculations; vascular age (years) is the age of vessels older than biological age or the same as the biological age.

the most central hemodynamic parameters including vascular age were better in patients treated with ACEI than in those treated with ARB. Our results indicate a gap between routine clinical practice and evidence-based guidelines in Indian settings and identify a need to reevaluate the current antihypertensive prescription strategy. Our study also suggests the use of CABP in routine practice to achieve the optimal management of hypertension.

\section{Data Availability}

The data used to support the findings of this study are available with the corresponding author and can be made available upon request.

\section{Conflicts of Interest}

The authors declare that they have no conflicts of interest.

\section{References}

[1] J. Mackay and G. Mensah, Atlas of heart disease and stroke, World Health Organization, 2004.

[2] P. M. Kearney, M. Whelton, K. Reynolds, P. Muntner, P. K. Whelton, and J. He, "Global burden of hypertension: analysis of worldwide data," The Lancet, vol. 365, no. 9455, pp. 217223, 2005

[3] R. Anchala, N. K. Kannuri, H. Pant et al., "Hypertension in India: a systematic review and meta-analysis of prevalence, awareness, and control of hypertension," Journal of Hypertension, vol. 32, no. 6, pp. 1170-1177, 2014.

[4] C. Vlachopoulos, K. Aznaouridis, M. F. O'Rourke, M. E. Safar, K. Baou, and C. Stefanadis, "Prediction of cardiovascular events and all-cause mortality with central haemodynamics: a systematic review and meta-analysis," European Heart Journal, vol. 31, no. 15, pp. 1865-1871, 2010.

[5] M. N. Doumas, E. Gkaliagkousi, N. Katsiki, A. Reklou, A. Lazaridis, and A. Karagiannis, "The effect of antihypertensive drugs on arterial stiffness and central hemodynamics: not all fingers are made the same," The Open Hypertension Journal, vol. 5, no. 1, pp. 75-81, 2013.

[6] P. Palatini, E. Casiglia, J. Gąsowski et al., "Arterial stiffness, central hemodynamics, and cardiovascular risk in hypertension," Vascular Health and Risk Management, vol. 7, pp. 725-739, 2011.

[7] M. E. Safar, J. Blacher, B. Pannier et al., "Central pulse pressure and mortality in end-stage renal disease," Hypertension, vol. 39, no. 3, pp. 735-738, 2002.

[8] M. J. Roman, R. B. Devereux, J. R. Kizer et al., "Central pressure more strongly relates to vascular disease and outcome than does brachial pressure: the Strong Heart Study," Hypertension, vol. 50, no. 1, pp. 197-203, 2007.

[9] R. Pini, M. C. Cavallini, V. Palmieri et al., "Central but not brachial blood pressure predicts cardiovascular events in an unselected geriatric population: the ICARe Dicomano Study," Journal of the American College of Cardiology, vol. 51, no. 25, pp. 2432-2439, 2008.

[10] A. Avolio, "Central aortic blood pressure and management of hypertension: confirmation of a paradigm shift?," Hypertension, vol. 62, no. 6, pp. 1005-1007, 2013.

[11] CAFE Steering Committee and Writing Committee, B. Williams, P. S. Lacy et al., "Differential impact of blood pressure-lowering drugs on central aortic pressure and clinical Outcomes," Circulation, vol. 113, no. 9, pp. 1213-1225, 2006.

[12] C. H. Manisty and A. D. Hughes, "Meta-analysis of the comparative effects of different classes of antihypertensive agents on brachial and central systolic blood pressure, and augmentation index," British Journal of Clinical Pharmacology, vol. 75, no. 1, pp. 79-92, 2013.

[13] A. D. Protogerou, G. S. Stergiou, C. Vlachopoulos, J. Blacher, and A. Achimastos, "The effect of antihypertensive drugs on central blood pressure beyond peripheral blood pressure. Part II: evidence for specific class-effects of antihypertensive drugs on pressure amplification," Current Pharmaceutical Design, vol. 15, no. 3, pp. 272-289, 2009.

[14] I. G. Horváth, Á. Németh, Z. Lenkey et al., "Invasive validation of a new oscillometric device (Arteriograph) for measuring 
augmentation index, central blood pressure and aortic pulse wave velocity," Journal of Hypertension, vol. 28, no. 10, pp. 2068-2075, 2010.

[15] A. L. Pauca, M. F. O’Rourke, and N. D. Kon, "Prospective evaluation of a method for estimating ascending aortic pressure from the radial artery pressure waveform," Hypertension, vol. 38, no. 4, pp. 932-937, 2001.

[16] W. Weiss, C. Gohlisch, C. Harsch-Gladisch, M. Tölle, W. Zidek, and M. van der Giet, "Oscillometric estimation of central blood pressure: validation of the Mobil-O-Graph in comparison with the SphygmoCor device," Blood Pressure Monitoring, vol. 17, no. 3, pp. 128-131, 2012.

[17] O. Narayan, J. Casan, M. Szarski, A. M. Dart, I. T. Meredith, and J. D. Cameron, "Estimation of central aortic blood pressure: a systematic meta-analysis of available techniques," Journal of Hypertension, vol. 32, no. 9, pp. 1727-1740, 2014.

[18] T. Weber, S. Wassertheurer, M. Rammer et al., "Validation of a brachial cuff-based method for estimating central systolic blood pressure," Hypertension, vol. 58, no. 5, pp. 825-832, 2011.

[19] R. Kelly, C. Hayward, J. Ganis, J. Daley, A. Avolio, and M. O'Rourke, "Non-invasive registration of the arterial pressure pulse waveform using high-fidelity application tonometry," Journal of Vascular Medicine and Biology, vol. 3, pp. 142-149, 1989.

[20] M. O'Rourke, "Pulsatile arterial haemodynamics in hypertension," Australian and New Zealand Journal of Medicine, vol. 6, no. s2, pp. 40-48, 1976.

[21] I. Prkacin, P. Findri, P. Fekete, M. Pezic, A. Golub, and V. Vamsi, "Central blood pressure and pulse wave velocity in patients with resistant hypertension," Signa Vitae: Journal for Intesive Care and Emergency Medicine, vol. 14, Supplement 1, pp. 28-30, 2018.

[22] L. C. van Vark, M. Bertrand, K. M. Akkerhuis et al., "Angiotensin-converting enzyme inhibitors reduce mortality in hypertension: a meta-analysis of randomized clinical trials of renin-angiotensin-aldosterone system inhibitors involving 158, 998 patients," European Heart Journal, vol. 33, no. 16, pp. 2088-2097, 2012.

[23] C. Thomopoulos, G. Parati, and A. Zanchetti, "Effects of blood pressure lowering on outcome incidence in hypertension: 5 . Head-to-head comparisons of various classes of antihypertensive drugs - overview and meta-analyses," Journal of Hypertension, vol. 33, no. 7, pp. 1321-1341, 2015.

[24] G. A. Mensah and G. Bakris, "Treatment and control of high blood pressure in adults," Cardiology Clinics, vol. 28, no. 4, pp. 609-622, 2010.

[25] J. Prenissl, J. Manne-Goehler, L. M. Jaacks et al., "Hypertension screening, awareness, treatment, and control in India: a nationally representative cross-sectional study among individuals aged 15 to 49 years," PLoS Medicine, vol. 16, no. 5, article e1002801, 2019.

[26] M. R. Law, J. K. Morris, and N. J. Wald, "Use of blood pressure lowering drugs in the prevention of cardiovascular disease: meta-analysis of 147 randomised trials in the context of expectations from prospective epidemiological studies," BMJ, vol. 338, no. 1, article b1665, 2009.

[27] M. R. Law, N. J. Wald, J. K. Morris, and R. E. Jordan, "Value of low dose combination treatment with blood pressure lowering drugs: analysis of 354 randomised trials," BMJ, vol. 326, no. 7404, article 1427, 2003.
[28] W. Xu, S. I. Goldberg, M. Shubina, and A. Turchin, “Optimal systolic blood pressure target, time to intensification, and time to follow-up in treatment of hypertension: population based retrospective cohort study," BMJ, vol. 350, no. 9, p. h158, 2015.

[29] P. K. Whelton, R. M. Carey, W. S. Aronow et al., "2017 ACC/AHA/AAPA/ABC/ACPM/AGS/APhA/ASH/ASPC/N$\mathrm{MA} / \mathrm{PCNA}$ guideline for the prevention, detection, evaluation, and management of high blood pressure in adults: executive summary: a report of the American College of Cardiology/American Heart Association Task Force on Clinical Practice Guidelines," Hypertension, vol. 71, no. 6, pp. 1269-1324, 2018.

[30] B. Williams, G. Mancia, W. Spiering et al., "2018 ESC/ESH guidelines for the management of arterial hypertension," European Heart Journal, vol. 39, no. 33, pp. 3021-3104, 2018.

[31] K. A. Nerenberg, K. B. Zarnke, A. A. Leung et al., "Hypertension Canada's 2018 guidelines for diagnosis, risk assessment, prevention, and treatment of hypertension in adults and children," The Canadian Journal of Cardiology, vol. 34, no. 5, pp. 506-525, 2018.

[32] On behalf of the EUROPA-PERGENE investigators, J. J. Brugts, M. P. M. de Maat et al., "The rationale and design of the PERindopril GENEtic association study (PERGENE): a pharmacogenetic analysis of angiotensin-converting enzyme inhibitor therapy in patients with stable coronary artery disease," Cardiovascular Drugs and Therapy, vol. 23, no. 2, pp. 171-181, 2009.

[33] J. J. Brugts, C. A. den Uil, A. H. Danser, and E. Boersma, "The renin-angiotensin-aldosterone system: approaches to guide angiotensin-converting enzyme inhibition in patients with coronary artery disease," Cardiology, vol. 112, no. 4, pp. 303312, 2009.

[34] J. J. Brugts, A. Isaacs, M. P. M. de Maat et al., "A pharmacogenetic analysis of determinants of hypertension and blood pressure response to angiotensin-converting enzyme inhibitor therapy in patients with vascular disease and healthy individuals," Journal of Hypertension, vol. 29, no. 3, pp. 509-519, 2011.

[35] F. Cosentino, P. J. Grant, V. Aboyans et al., "2019 ESC guidelines on diabetes, pre-diabetes, and cardiovascular diseases developed in collaboration with the EASD," European Heart Journal, vol. 41, no. 2, pp. 255-323, 2020.

[36] E. J. Kroeker and E. H. Wood, "Comparison of simultaneously recorded central and peripheral arterial pressure pulses during rest, exercise and tilted position in man," Circulation Research, vol. 3, no. 6, pp. 623-632, 1955.

[37] A. L. Pauca, S. L. Wallenhaupt, N. D. Kon, and W. Y. Tucker, "Does radial artery pressure accurately reflect aortic pressure?," Chest, vol. 102, no. 4, pp. 1193-1198, 1992.

[38] T. J. McGaughey, E. A. Fletcher, and S. A. Shah, "Impact of antihypertensive agents on central systolic blood pressure and augmentation index: a meta-analysis," American Journal of Hypertension, vol. 29, no. 4, pp. 448-457, 2016.

[39] L. Ruilope and A. Schaefer, "The fixed-dose combination of olmesartan/amlodipine was superior in central aortic blood pressure reduction compared with perindopril/amlodipine: a randomized, double-blind trial in patients with hypertension," Advances in Therapy, vol. 30, no. 12, pp. 1086-1099, 2013. 